\title{
Influence of gastronomic improvement of a menu on consumers' perceived wellbeing in a real context study
}

\author{
María Mora, Gabriel López-Font, Elena Urdaneta, Laura Vázquez-Araújo, \\ Leticia Coello-Lafuente, Carolina Chaya
}

\begin{abstract}
A B S T R A C T
Overweight is one of the main health problems associated with food habits, and has been associated with decreasing levels of wellbeing. Determining the influence of foods on people's perceived wellbeing could help understanding food choices, and therefore promoting healthy habits. The aim of the present study was to investigate the influence of a gastronomically improved menu on consumers' perceived wellbeing. Two weight loss diet menus were designed with the same ingredients and caloric content; one of them was a traditional menu, and the other one was gastronomically improved: appearance, textures, and flavors were enhanced. Both menus were tasted in a real context by 71 women who had been on a weight loss diet during the last year. Consumers attended the study two different days during consecutive weeks. Participants rated liking and perceived wellbeing after the consumption of each menu. The gastronomic improvement of the meal increased liking scores and perceived wellbeing of consumers, particularly in the emotional, social and spiritual dimensions.
\end{abstract}

\section{Introduction}

Studying consumers' acceptance and hedonic perception of products have been proven as key indicators of the success of foods in the market (Tuorila, 2007), but some authors have shown that other aspects related to food consumption were also important to understand the decisionmaking process (e.g.: Köster, 2009). Some of these factors were related to not only the product characteristics, but also to consumers' characteristics, such as: physiological, psychological, cultural, and social aspects. McMahon, O'Shea, Tapsell and Williams (2014) and Meiselman (2016) reported that understanding the influence of food on the perceived wellbeing of consumers can contribute to a better understanding of food choices. Wellbeing perception and its relationship with food have become relevant aspects to consider when developing consumer studies (Meiselman, 2016). Wellbeing is a broad concept that lacks a unique definition (Dodge et al., 2012), but some papers have defined it as "the holistic evaluation of people's life" (Meiselman, 2016; Miller and Foster, 2010).

It has been widely demonstrated that a person's perceived wellbeing might be affected by food, not only because food has a direct impact on a person's health, but also because food affects emotions and has an influence on the social relationships of the person (Shimizu, 2003). Different authors have investigated the different dimensions which compose wellbeing, but Adams et al. (1997) reported that most foodrelated studies used a 5 dimension model, which includes: physical, intellectual, emotional, social, and spiritual dimensions (e.g., Ares et al., 2015; Ares et al., 2016; King et al., 2012; King et al., 2015). Doll, Petersen and Stewart-Brown (2000) reported that, in a study conducted with more than 8000 volunteers, overweight and obesity were associated with decreasing levels of both physical and emotional wellbeing, highlighting the importance in the physical dimension. In addition, Ares et al. (2014) reported that wellbeing in a food-related context was strongly associated with physical health. Authors of the Wellsense Profile $^{\mathrm{TM}}$ identified the physical dimension as the most relevant for consumers when asked to define wellness in a food-related context (King et al., 2015).

The main health problems associated with food habits are overweight and obesity, which in turn are directly linked to other health issues such as cardiovascular diseases, type II diabetes, cancer, and metabolic syndrome. Beaglehole et al. (2011) and Strong et al. (2006) 
Table 1

Menu description.

\begin{tabular}{ll}
\hline Conventional diet menu (625 kcal) & Gastronomical improved menu (625 kcal) \\
\hline Boiled broccoli and carrots & Broccoli cous-cous with raw carrots and broccoli marrows \\
Grilled chicken with a side of boiled potatoes & Smoked chicken with papas arrugás \\
Slice of pineapple & Grilled pineapple flavored with licorice and vanilla as the dessert \\
Bread & Bread \\
$\quad$ Olive oil and salt & Olive oil and salt \\
\hline
\end{tabular}

concluded that some of the solutions to fight overweight and obesity were linked to engage with healthy eating habits. McMahon, Williams and Tapsell (2010) proposed studying how consumers perceived the relationship between food and their subjective wellbeing to understand consumer food choices. This knowledge could contribute to the development of efficient strategies for modifying consumers' eating patterns. To the authors' knowledge, there is no published research about the relationship between perceived wellbeing and food choice drivers of consumers on a real context of consumption.

Some of the main strategies to decrease the incidence of overweight in the general population are promoting exercise and following weight loss diets, in which the energy intake of the person needs to be below his total energy expenditure. Successful adherence to calorie restriction regimes might be extremely challenging, because the design of the meal does not generally aim food enjoyment (Forde, 2016). One of the procedures to improve adherence might be designing the diet taking into consideration the preferences of the person, while remaining aligned with the nutritional requirements (Gibson and Sainsbury, 2017). Although some authors have shown that improved palatability increased energy intake (Blundell and Stubbs, 1999), it has also been proven that sensory rewarding might lead to a lower caloric intake (Møller, 2015). Taste, smell, texture, and all sensory attributes of a food contribute to the overall satiation and therefore the regulation of energy intake (Møller, 2015). Some areas of gastronomy include the knowledge and activities related to ingredients, recipes, and culinary techniques applied to foods; this knowledge could be helpful to increase diet adherence and consumers' satisfaction by breaking the association between feelings of deprivation with the weight loss process (Forde, 2016).

The hypothesis of the present study was that a gastronomically improved menu could increase the perceived wellbeing of consumers concerned by their weight; the study was conducted in a real context of consumption to favor that all wellbeing dimensions were properly perceived and rated by consumers.

\section{Material and methods}

\section{Menus}

To decide which menus should be prepared, a 4-h discussion session with eight chefs and three nutritionists from Basque Culinary Center (BCC) was carried out. The session was designed to promote creativity and teamwork between chefs and nutritionists. The session was divided into two parts: during the first part, participants defined individually the concept of a "conventional diet menu", and then they shared and discussed their ideas to reach a consensus. The "conventional diet menu" defined by the group was composed of boiled broccoli and carrots as starter, grilled chicken breast with a side of boiled potatoes as a main course, and a slice of pineapple as a dessert. During the second part, the discussion aimed at developing gastronomical improvements to the conventional diet menu, focusing on innovation mainly driven by culinary techniques. A consensus was reached by the group on the entrée, main course and dessert: to substitute the boiled broccoli and carrots with a broccoli couscous (a modern cuisine preparation that consists of blitzing the florets of the broccoli in a food processor to obtain a loose meal that resembles couscous) with garlic olive oil and sticks of carrots on the top, to smoke the chicken breast and then cook it in the oven, and to grill the pineapple in a pan and add spices (licorice and vanilla). The side of potatoes inspired four different ideas: 1 ) potato gnocchi, 2) crispy potatoes stretched and cooked in the oven, 3) minced potatoes grilled in the oven, and 4) papas arrugás (a Spanish recipe consisting on potatoes boiled with salt, which produces a wrinkled skin in the potato). After testing the appearance of the 4 options, the 3 first ones were discarded because the volume of the side potatoes was much greater than the main course (chicken breast) and also the preparations were harder to standardize. Because of the importance of the reproducibility of both menus throughout the study, the papas arrugás recipe was the selected one.

Both conventional and gastronomically improved menus had the same quantities of the same raw materials (chicken, broccoli, carrot, potatoes, bread, and pineapple) and the same caloric content: $625 \mathrm{kcal}$ (Table 1). To avoid biases, all menus were cooked by the same chef during the whole experiment, and all cooking parameters were standardized (raw material weights, cooking times, temperatures, portion sizes, and plating).

\section{Consumer test}

\section{Consumer recruitment}

The Spanish National Institute of Statistics reported in 2018 that the incidence of women who were on a weight loss diet was $\sim 30 \%$ higher than men (Instituto Nacional de Estadística, June 2018); therefore, female consumers were chosen for the study. Eligibility criteria for participating in the study were: i) being or having been during the last year on a weight loss diet, ii) being $30-70$ years old, and iii) not having health problems related to food (diabetes, hyperlipidemia, etc.).

Recruitment was done using posters that were exhibited in different places in the city: health care centers, cultural centers, libraries, gyms, women associations and universities. Once the consumer contacted the research team, a set of screening questionnaires was sent by email, including questions on neophobia (the Spanish version of the Food Neophobia Scale, reported by Fernández-Ruiz et al., 2013) and health consciousness (the Spanish version of the Health Consciousness Questionnaire reported by Mialon et al., 2002 and Schifferstein and Oude Ophuis, 1998; translated by Baixauli et al., 2008), to guarantee that the consumers would not reject the meal and that all participants were concerned about their health. Consumers whose neophobia ratings were $\geq 50$, on a scale ranging from 10 to 70 , and/or those with health consciousness ratings $\leq 33$, on a scale ranging from 15 to 105 , were excluded. Also, a sociodemographic questionnaire, and an adaptation for Spanish consumers of the Food Choice Questionnaire (FCQ) developed by Steptoe et al. (1995) (Jáuregui-Lobera and Bolaños Ríos, 2011) were included during the screening phase. The original FCQ (Steptoe et al., 1995) had 36 items divided into nine dimensions (health, mood, convenience, sensory appeal, natural content, price, weight) while the adapted FCQ for Spanish consumers included 34 items divided into seven dimensions (convenience, health-natural content, price, mood, sensory appeal, weight control and familiarity), and helped understanding the motivations of food choice and therefore characterizing consumers. The participants who reported allergies, intolerances and/ or aversion to some of the ingredients included in the menus, were discarded. 
Participants who passed the screening criteria were asked to come with one to three friends or relatives because, generally, meals are a shared moment in Spain, and wellbeing has a social dimension which needed to be considered. The companions had to fill out all questionnaires and meet the same screening criteria, before being included in the experiment.

Recruitment was a challenging step in this research due to the complexity of the experiment. Only $33 \%$ of the initial volunteers was finally recruited. A final consumer panel consisting on 71 female volunteers (32-67 years old) evaluated the meal samples in the restaurant at BCC in Donostia-San Sebastián (Spain).

\section{Test location and procedure}

The experiment was conducted at the BCC restaurant because the study was planned with a real context approach, and real context is considered good practice for meal research (Lahne, 2018). The restaurant at BCC has a combination of natural and artificial light and is acclimatized at approximately $21^{\circ} \mathrm{C}$.

The same table was used for all experiments at lunchtime, and the same waiter served the customers following a standardized procedure. Participants had to come twice, in consecutive weeks, to test the conventional and the improved menu. To avoid biases, half of them first tasted the conventional menu, and the other half first tasted the gastronomically improved menu. Consumers were instructed to eat as much as they wanted; over $97 \%$ of consumers ate the whole menu.

In addition, with the aim of characterizing participants in detail, the body composition information (e.g.: Body Mass Index - BMI in $\mathrm{kg} \mathrm{m}^{-2}$ ) of each consumer was recorded using Bioelectrical Impedance Analysis (BIA).

\section{Questionnaires}

In addition to the questionnaires filled out during the screening phase, every tasting day, at the end of the meal, participants first answered the question, "Please rate how much you like the menu that you have just consumed" using a $9 \mathrm{~cm}$ linear scale anchored in the extremes with "extremely dislike" and "extremely like", and then completed the wellbeing questionnaire, "Based on the menu that you have just consumed, please indicate your level of agreement/disagreement with the following statements". The wellbeing questionnaire was developed by Ares et al. (2016) and included 31 items to be scored from "completely disagree" to "completely agree" on a 7-point scale. This wellbeing questionnaire included a general evaluation of wellbeing, as well as items related to its five main dimensions: physical, intellectual, emotional, social and spiritual. Additionally, three extra items were included in the final wellbeing questionnaire: "It makes me feel adventurous", "I enjoy", and "I get bored". The order of the different items of the wellbeing questionnaire were randomized for each consumer. Data collection was done on paper format using FIZZ software (Biosystemes, Dijon, France). Questionnaire structure is shown in Table 2.

\section{Data analysis}

With the aim of characterizing the sample population who participated in the study, consumers were grouped into clusters according to

Table 2

Questionnaire structure.

\begin{tabular}{ll}
\hline QUESTION & MEASUREMENTS \\
\hline Acceptability & $\begin{array}{l}9 \text { cm linear scale anchored in the extremes with } \\
\text { "extremely dislike" and "extremely like" } \\
\text { Wellbeing questionnaire (Ares et al., 2016) }\end{array}$ \\
Wellbeing perception & 31 items \\
Emotional extra items & It makes me feel adventurous \\
& I enjoy \\
& I get bored
\end{tabular}

the motives that determine their food choices, using hierarchical cluster analysis (HCA). As aforementioned, FCQ contains 34 items classified into seven different dimensions; the means of the items of every dimension were computed for each consumer, and a matrix was built with consumers as observations (rows) and dimensions as variables (columns). Consumers were grouped in clusters using Euclidean distance and Ward's criterion of aggregation (XLSTAT Version, 2009.6.03, Addinsoft, USA).

To determine if both menus elicited significantly different hedonic and wellbeing response, data from the acceptability and wellbeing items were input into a two-way mixed ANOVA with menu as a fixed effect and consumer as a random effect (Statgraphics Centurion XVII version).

\section{Results}

\section{Consumers' characteristics: BMI and Food Choice Questionnaire}

Results of Bioelectrical Impedance Analysis showed a wide range of characteristics, being $25 \%$ of consumers characterized by a Body Mass Index (BMI) between 18.5 and $24.99 \mathrm{~kg} \mathrm{~m}^{-2}$ (normal weight), $37 \%$ of consumers characterized by a BMI between 25.00 and $29.99 \mathrm{~kg} \mathrm{~m}^{-2}$ (overweight) and $38 \%$ of consumers characterized by a BMI $\geq 30 \mathrm{~kg} \mathrm{~m} \mathrm{~m}^{-2}$ (obese). Underweighted consumers (BMI $<18.5 \mathrm{~kg} \mathrm{~m}^{-2}$ ) were nor represented in the present study because one of the aims was determining the influence of some gastronomy tools on the wellbeing of consumers who were or had being on a lose weight diet recently, and underweighted consumers would not fit on that screening criteria.

Consumers were grouped depending on their food choice motives using the means of the different items belonging to the FCQ dimensions, which are shown in Fig. 1. Hierarchical cluster analysis showed that consumers were grouped into 4 clusters ( $\mathrm{C} 1$ to $\mathrm{C} 4$ ). Fig. 1 shows the cluster profiles for the 7 dimensions of food choice: convenience, health-natural content, price, mood, sensory appeal, weight control and familiarity. ANOVA and Tukey tests revealed that all dimensions were significantly different between groups (results not shown). Group 1 (C1; $\mathrm{n}=18$ ) was characterized by giving great importance to all dimensions except familiarity. Group $2(\mathrm{C} 2 ; \mathrm{n}=17)$ was characterized by reporting higher averages on health-natural content, sensory appearance and familiarity. Group 3 (C3; $n=18$ ) reported the lowest ratings on mood and familiarity dimensions. Finally, Group $4(\mathrm{C} 4 ; \mathrm{n}=18)$ was characterized by reporting the lowest ratings on the health-natural content, price, and weight control dimensions. Results of this section should be considered tentative due to the limited sample size of each one of the clusters, but showed a varied range of food choice patterns and a starting point for further analysis on this matter.

\section{Effect of the gastronomic improvement of a weight loss diet menu on perceived wellbeing}

Significant differences in the hedonic response were found between menus ( $\mathrm{p}<0.05$ ). Although both menus denoted liking, the gastronomically improved menu was more liked than the conventional one (Table 3). The effect of the menu on the perception of wellbeing for the studied population was significant in 19 of the 31 items, as well as in the 3 extra items. No significant differences were detected when consumers were asked about their perception of general wellbeing associated to the menus (G1 in Table 3), but consumers reported that the improved menu made them "feel better" than the conventional one (G2). Additionally, when evaluating the specific items that were included in the wellbeing concept, some specific differences were found.

The improved menu did not have any significant effect on the items of the intellectual dimension of wellbeing. Only 3 items belonging to the physical dimension were significantly different between menus (P3, P4, and P7 in Table 3), highlighting that P4 ("It helps me control my 


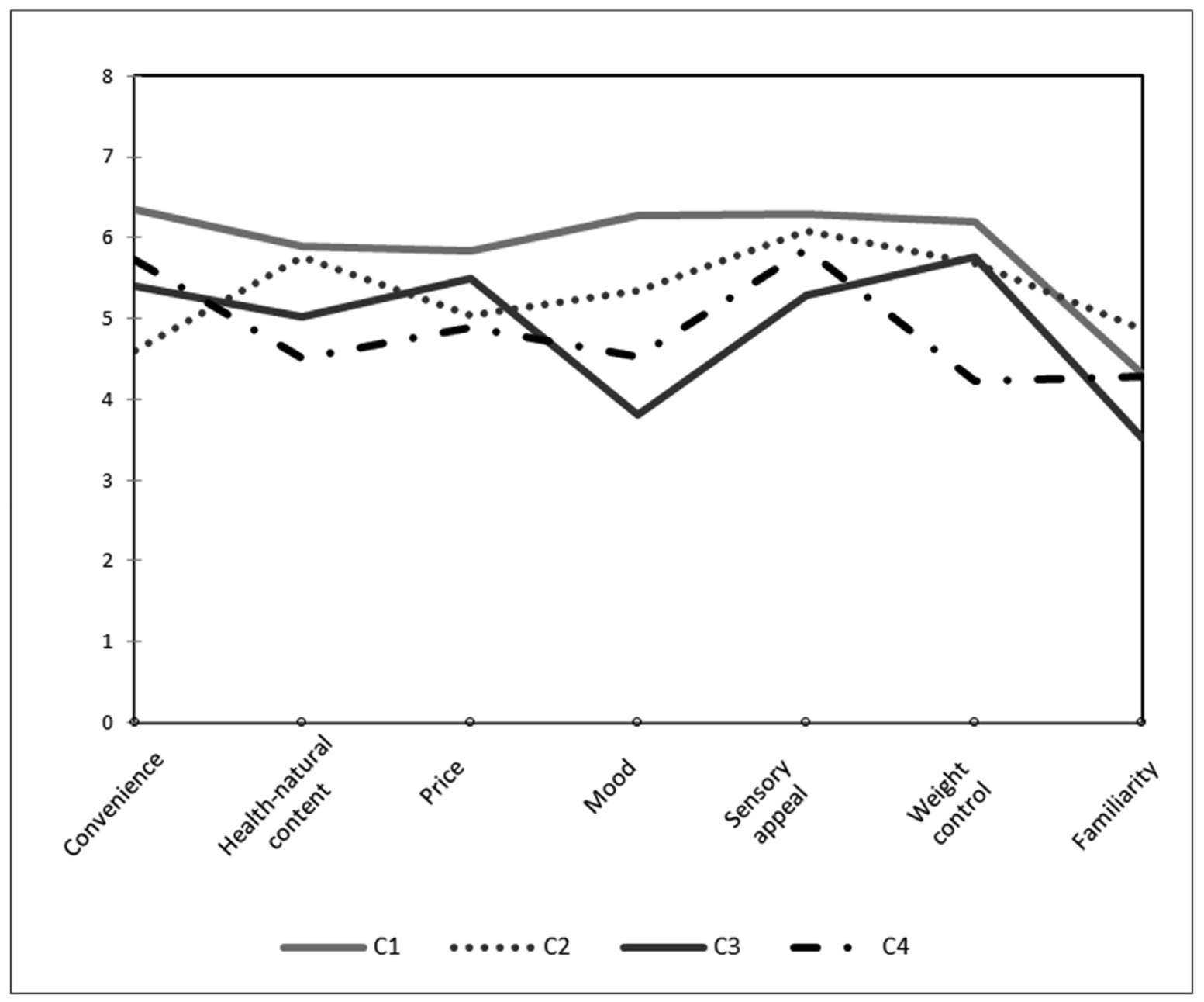

Fig. 1. Consumers' profiles depending on the food choice clusters ( $\mathrm{C} 1$ to $\mathrm{C} 4$ ).

weight") was better scored in the conventional menu than in the improved one. The emotional, social, and spiritual dimensions seemed to be the dimensions for which the gastronomical improvement had a greater influence: several items associated to these dimensions were significantly different in both menus (Table 3 ).

In general, the improved menu received higher scores than the conventional menu in all significantly different items. Only 3 of the items received higher scores in the conventional menu than on the improved one: P4 (It helps me control my weight), E6 (It makes me feel sad) and EX3 (I get bored) (Fig. 2). Consumers associated the conventional menu with some negative feelings (e.g.: boredom, sadness). They also perceived that the improved menu would have a lower impact on their weight loss objective.

\section{Discussion}

The present study shows the influence of an improved menu on consumers' perceived wellbeing in a female consumer segment characterized by being concerned about their health, but with a diverse profile regarding body mass index and food choice patterns. A real context approach was used because a wellbeing investigation needs to take into consideration all the dimensions of wellbeing, including the social one. Results of the present study showed that the gastronomic improvement of the meal increased the liking scores and perceived wellbeing of participants.

Several researchers have found a positive effect of liking when modifying single sensory modalities of food such as aroma, texture, or appearance (Herz and Engen, 1996; Tobin, O'Sullivan, Hamill and
Kerry, 2012; Zellner et al., 2014). The present study was conducted in a restaurant and modifying several sensory properties of a whole meal, considering this a more realistic approach for determining differences in food-related behavior (Lahne, 2018).

In general, as mentioned during the results paragraph, the improved menu had a significant influence on liking and on 18 of the 34 wellbeing items evaluated in the present study. The improved menu obtained significantly higher ratings on liking and on most of the different items of the wellbeing perception. The main gastronomical improvements of the menu were: adding spices (and therefore the aromatic intensity and descriptors associated with the menu), modifying the textures, and changing the overall appearance of the meal. King et al. (2015) reported that the addition of spices in recipes for meatloaf and vegetables increased the wellness perception of consumers, suggesting that the use of spices might increase the positive "subjective experience" associated with a meal. It might be possible that in both studies sensory reward caused the modification of the wellbeing perception associated with the improved menus. In the present study, gastronomical improvements affected not only aroma and flavor but also other sensory modalities (texture, taste, and appearance). Therefore, it was not possible to know if the influence on liking and on consumer wellbeing perception was due to one of them (e.g., aroma or flavor enhancement due to the addition of spices), to some specific combination, or to a more holistic evaluation.

Analyzing the general items on the wellbeing scale, the response to the statement "It is good for my wellbeing" was not significantly different between menus, but significant differences were found for the "It makes me feel good" statement. Ares et al. (2016) suggested that the expression 
Table 3

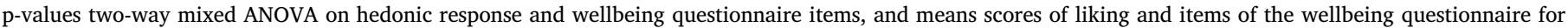
both menus: Conventional (CM) and Gastronomical improved (GM).

\begin{tabular}{|c|c|c|c|c|}
\hline & & p-values & Means CM & Means GM \\
\hline \multicolumn{2}{|c|}{ Hedonic rating $(\mathrm{H})$} & $<0.0001^{* * *}$ & 5,5 & 6,6 \\
\hline Dimension & Wellbeing items & & & \\
\hline \multirow[t]{2}{*}{ General } & It is good for wellbeing (G1) & 0.545 & 5,9 & 6,0 \\
\hline & It makes me feel good (G2) & $0.005^{* *}$ & 5,1 & 5,7 \\
\hline \multirow[t]{7}{*}{ Physical } & It is good for my health (P1) & 0.680 & 6,4 & 6,4 \\
\hline & It is nutritious (P2) & 0.290 & 6,1 & 6,3 \\
\hline & It makes me feel satiated (P3) & $0.011 *$ & 5,2 & 5,8 \\
\hline & It helps me control my weight (P4) & $0.009 * *$ & 6,4 & 6,0 \\
\hline & It keeps me fit (P5) & 0.218 & 5,9 & 5,8 \\
\hline & It keeps me healthy (P6) & 0.490 & 6,2 & 6,1 \\
\hline & It gives me energy (P7) & $0.021^{*}$ & 4,9 & 5,4 \\
\hline \multirow[t]{5}{*}{ Intellectual } & It keeps me alert (I1) & 0.537 & 4,0 & 4,2 \\
\hline & It improves my mental performance (I2) & 0.305 & 4,2 & 4,4 \\
\hline & It improves my memory (I3) & 0.081 & 3,8 & 4,2 \\
\hline & It helps me concentrate (I4) & 0.119 & 3,8 & 4,2 \\
\hline & It makes me think clearly (I5) & $0.029 *$ & 3,8 & 4,2 \\
\hline \multirow[t]{7}{*}{ Emotional } & It makes me feel calm and relaxed (E1) & $0.003^{* *}$ & 4,0 & 4,7 \\
\hline & It makes me feel guilty (E2) & 0.837 & 1,9 & 1,9 \\
\hline & It gives me pleasure (E3) & $<0.0001 * *$ & 3,8 & 4,8 \\
\hline & It makes me feel excited (E4) & $<0.0001^{* *}$ & 3,7 & 4,8 \\
\hline & It makes me feel satisfied (E5) & $0.001 * *$ & 4,9 & 5,5 \\
\hline & It makes me feel sad (E6) & $0.002 * *$ & 2,5 & 1,8 \\
\hline & It makes me feel happy (E7) & $<0.0001^{* *}$ & 4,3 & 5,0 \\
\hline \multirow[t]{5}{*}{ Social } & It is good for sharing with family (S1) & $0.001 * *$ & 4,9 & 5,6 \\
\hline & It makes me feel connected to others ( $\mathrm{S} 2$ ) & $0.039 *$ & 3,8 & 4,3 \\
\hline & It improves what others think of me (S3) & 0.086 & 3,5 & 3,9 \\
\hline & It makes me feel supported by others (S4) & $0.017^{*}$ & 3,4 & 3,9 \\
\hline & It is good for sharing with friends (S5) & $<0.0001 * *$ & 4,5 & 5,6 \\
\hline \multirow[t]{5}{*}{ Spiritual } & It makes my life closer to my ideal (SP1) & 0.051 & 4,4 & 4,8 \\
\hline & It makes me feel closer to nature (SP2) & $0.005^{* *}$ & 4,3 & 4,8 \\
\hline & It gives me a sense of gratitude (SP3) & $0.001 * *$ & 4,1 & 4,8 \\
\hline & It gives me inner peace (SP4) & $0.001 * *$ & 3,8 & 4,5 \\
\hline & It is good for my soul (SP5) & $0.023^{*}$ & 3,9 & 4,4 \\
\hline \multirow[t]{3}{*}{ Extra } & It makes me feel adventurous (EX1) & $<0.0001^{* *}$ & 2,9 & 4,0 \\
\hline & I enjoy (EX2) & $<0.0001^{* *}$ & 3,3 & 4,9 \\
\hline & I get bored (EX3) & $0.006^{* *}$ & 3,6 & 2,8 \\
\hline
\end{tabular}

$*$, **, significant $\mathrm{p}<0.05, \mathrm{p}<0.01$ respectively.

Indicated, in brackets, abbreviations for each item to ease discussion and figures reading.

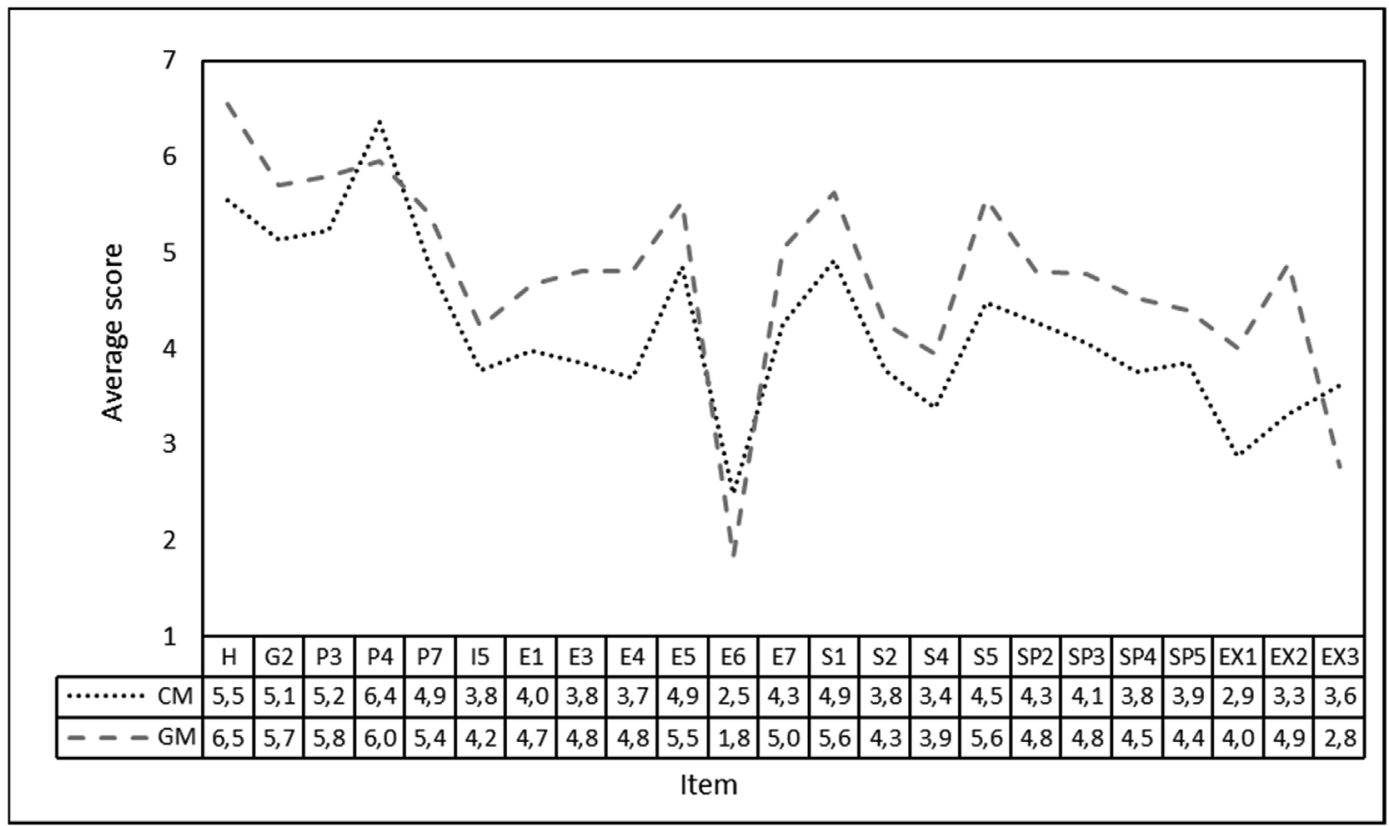

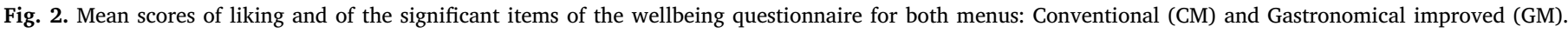
Legend. Information on the meaning of each item is shown in Table 3. 
"feeling good" could represent a more holistic measure of the influence of foods on consumers" life than using the term "wellbeing", and that "feeling good" could increase the importance of the emotional aspects of wellbeing.

The wellbeing dimensions with a higher number of items affected by the gastronomic improvement were the emotional, social, and spiritual dimensions. The fact that the emotional dimension was one of the most affected was expected, considering the multimodal sensory differences and the link between sensory perception and emotional response (Beyts et al., 2017; Chaya et al., 2015; Jager et al., 2014; Mojet et al., 2015; Mora et al., 2019; Mora et al., 2018; Ng et al., 2013; Silva et al., 2017; Thomson et al., 2010). Several authors have reported that measuring all five dimensions of wellbeing was very important when testing food, because different food products influenced in different ways the diverse wellness dimensions (Ares et al., 2016; King et al., 2015). Contrary to our findings, some studies revealed the physical dimension of wellbeing to be the most affected by food products (Ares et al., 2014, 2015; King et al., 2015; Oliveira et al., 2017; Reis et al., 2017), and that physical dimension might be clearly linked to a healthy diet (Miller and Foster, 2010). Results of the present study reported that responses for the physical dimension showed a limited association with the menu effect (3 of 7 items). However, other authors found a higher impact on the physical dimension when comparing very different product categories (for example, chocolate $v s$ apples) (Ares et al., 2015). In this study, the main ingredients (products) of both menus were the same, and therefore, it could be that the "healthy" character of the meals was perceived as similar by consumers. As reported by Ares et al. (2016), the "wellbeing" term could be strongly associated with health aspects; this could explain the lack of significant differences between menus when studying the physical dimension as well as the general term "It is good for my wellbeing". In addition, because this study was conducted in a real context approach, the results might be different from the previous studies which were conducted in a tasting room context (e.g., King et al., 2015; Oliveira et al., 2017; Reis et al., 2017) or using an online survey where the stimuli were images of food (Apaolaza, Hartmann, D'Souza and López, 2018; Ares et al., 2015). The real context could have enhanced the social, emotional and spiritual dimensions of well-being perception.

One of the items with a different response pattern was "It helps me control my weight". Although both menus had the same caloric content (information that consumers did not have), this item received a lower score for the improved menu than for the conventional one. In general, consumers on a loss weight diet have the common belief that a pleasant and enjoyable meal has a higher caloric content than a conventional one, and therefore relate "losing weight" with "suffering" and "delicious food deprivation". Although the item "It helps me control my weight" belongs to the physical dimension, it could had been directly related to an emotional aspect in the present consumers' responses.

Food choice is a complex process influenced by product characteristics, personal characteristics, and their interaction in a particular context (Köster, 2009). Many authors proposed the study of the relationship between food and subjective wellbeing as a way to have a better understanding of consumers' food choices and to develop efficient strategies for modifying eating patterns (e.g., Ares et al., 2014; Ares et al., 2016; Oliveira et al., 2017; Reis et al., 2017). During the present study, different food choice patterns were included, and more consumers belonging to each segment need to be included to study the influence of the gastronomical improvement, food choice and wellbeing. Using this real context approach as a basis for future studies would facilitate understanding this complex interaction. Also, Doll et al. (2000) reported that overweight and obese consumers' segments were associated with reduced levels of physical and emotional wellbeing, highlighting the importance of the physical dimension, but the present study showed that the emotional dimension was significantly affected by the menu improvement. Studying the influence of wellbeing per-ception variation during long-term adherence to weight loss diets would be interesting to determine the relative importance of BMI and gastronomy.

\section{Conclusions}

In the context of this experiment, some tools of gastronomy have been proven useful to increase the hedonic rating of a weight loss meal. Additionally, most perceived wellbeing items were significantly affected by the sensory improvement of the menu, highlighting its influence on the emotional, social and spiritual dimensions. Results also suggested that the physical dimension of perceived wellbeing could be linked and vary depending on the assessed product, and not only to the individual. Further studies are needed to prove if weight loss diet adherence improves when wellbeing perception of the meal is higher, and therefore if gastronomy could be helpful in fighting obesity and if the use of culinary improvements could be included in some educational programs together with training in nutrition and dietetics. Future research, with a larger sample size, is needed to fully understand all factors involved in wellbeing perception (e.g.: food choice cluster of the consumer), but the real context approach seemed to be useful to detect variations in some of the wellbeing dimensions (e.g.: social) which might be less evident when conducting this kind of studies under controlled conditions (individual booths of taste rooms).

\section{Authorship contributions}

María Mora: Methodology, Investigation, Writing - Original Draft, Review \& Editing, Project administration.

Gabriel López-Font: Investigation, Formal analysis.

Elena Urdaneta: Investigation, Conceptualization.

Laura Vázquez-Araújo: Investigation.

Leticia Coello-Lafuente: Investigation.

Carolina Chaya: Methodology, Formal analysis, Supervision.

\section{Acknowledgements}

This work was supported by the Basque Government.

\section{References}

Adams, T., Bezner, J., Steinhardt, M., 1997. The conceptualization and measurement of perceived wellness: integrating balance across and within dimensions. Am. J. Health Promot. 11 (3), 208-218. https://doi.org/10.4278/0890-1171-11.3.208.

Apaolaza, V., Hartmann, P., D'Souza, C., López, C.M., 2018. Eat organic - feel good? The relationship between organic food consumption, health concern and subjective wellbeing. Food Qual. Prefer. 63, 51-62. https://doi.org/10.1016/j.foodqual.2017. 07.011.

Ares, G., de Saldamando, L., Giménez, A., Claret, A., Cunha, L.M., Guerrero, L., et al., 2015. Consumers' associations with wellbeing in a food-related context: a cross-cultural study. Food Qual. Prefer. 40, 304-315. https://doi.org/10.1016/j.foodqual. 2014.06.001.

Ares, G., De Saldamando, L., Giménez, A., Deliza, R., 2014. Food and wellbeing. Towards a consumer-based approach. Appetite 74, 61-69. https://doi.org/10.1016/j.appet. 2013.11.017.

Ares, G., Giménez, A., Vidal, L., Zhou, Y., Krystallis, A., Tsalis, G., et al., 2016. Do we all perceive food-related wellbeing in the same way? Results from an exploratory crosscultural study. Food Qual. Prefer. 52, 62-73. https://doi.org/10.1016/j.foodqual. 2016.03.014.

Baixauli, R., Salvador, A., Hough, G., Fiszman, S.M., 2008. How information about fibre (traditional and resistant starch) influences consumer acceptance of muffins. Food Qual. Prefer. 19 (7), 628-635. https://doi.org/10.1016/j.foodqual.2008.05.002.

Beaglehole, R., Bonita, R., Horton, R., Adams, C., Alleyne, G., Asaria, P., et al., 2011. Priority actions for the non-communicable disease crisis. Lancet 377 (9775), 1438-1447. https://doi.org/10.1016/s0140-6736(11)60393-0.

Beyts, C., Chaya, C., Dehrmann, F., James, S., Katherine, S., Hort, J., 2017. A comparison of self-reported emotional and implicit responses to aromas in beer. Food Qual. Prefer. 59, 68-80. https://doi.org/10.1016/j.foodqual.2017.02.006.

Blundell, J.E., Stubbs, R.J., 1999. High and low carbohydrate and fat intakes: limits imposed by appetite and palatability and their implications for energy balance. Eur. J. Clin. Nutr. 53 (1), 148-165 Supplement.

Chaya, C., Pacoud, J., Ng, M., Fenton, A., Hort, J., 2015. Measuring the emotional response to beer and the relative impact of sensory and packaging cues. J. Am. Soc. Brew. Chem. 73 (1), 49-60. https://doi.org/10.1094/asbcj-2015-0114-01. 
Dodge, R., Daly, A.P., Huyton, J., Sanders, L.D., 2012. The challenge of defining wellbeing. Int. J. Wellbeing 2 (3), 222-235. https://doi.org/10.5502/ijw.v2i3.4.

Doll, H.A., Petersen, S.E.K., Stewart-Brown, S.L., 2000. Obesity and physical and emotional well-being: associations between body mass index, chronic illness, and the physical and mental components of the SF-36 questionnaire. Obes. Res. 8 (2), 160-170. https://doi.org/10.1038/oby.2000.17.

Fernández-Ruiz, V., Claret, A., Chaya, C., 2013. Testing a Spanish-version of the food neophobia scale. Food Qual. Prefer. 28 (1), 222-225.

Forde, C.G., 2016. Flavor Perception and Satiation. Flavor Elsevier, pp. 251-276. https:// doi.org/10.1016/b978-0-08-100295-7.00012-8.

Gibson, A.A., Sainsbury, A., 2017. Strategies to improve adherence to dietary weight loss interventions in research and real-world settings. Behav. Sci. 7 (3), 44. https://doi. org $/ 10.3390 /$ bs7030044.

Herz, R.S., Engen, T., 1996. Odor memory: review and analysis. Psychon. Bull. Rev. 3 (3), 300-313. https://doi.org/10.3758/bf03210754.

Instituto Nacional de Estadística, June 2018. INE. Retrieved from. http://www.ine.es/.

Jager, G., Schlich, P., Tijssen, I., Yao, J., Visalli, M., De Graaf, C., Stieger, M., 2014. Temporal dominance of emotions: measuring dynamics of food-related emotions during consumption. Food Qual. Prefer. 37, 87-99. https://doi.org/10.1016/j. foodqual.2014.04.010.

Jáuregui-Lobera, I., Bolaños Ríos, P., 2011. What motivates the consumer's food choice? Nutr. Hosp. 26 (6).

King, S.C., Sainsbury, J., Meiselman, H.L., Snow, J., Gillette, M., McCafferty, D., 2012 Measuring the wellness in "health and wellness.". In: 5th European Conference on Sensory and Consumer Research: 9-12 September 2012. Bern, Switzerland.

King, S.C., Snow, J., Meiselman, H.L., Sainsbury, J., Carr, B.T., McCafferty, D., et al., 2015. Development of a questionnaire to measure consumer wellness associated with foods: the WellSense Profile ${ }^{\mathrm{TM}}$. Food Qual. Prefer. 39, 82-94. https://doi.org/10. 1016/j.foodqual.2014.06.003.

Köster, E.P., 2009. Diversity in the determinants of food choice: a psychological perspective. Food Qual. Prefer. 20 (2), 70-82. https://doi.org/10.1016/j.foodqual.2007. 11.002.

Lahne, J., 2018. Evaluation of meals and food pairing. In: In: Ares, G., Varela, P. (Eds.), Methods in Consumer Research, vol. 2. Woodhead Publishing, pp. 85-107. https:// doi.org/10.1016/B978-0-08-101743-2.00004-2.

McMahon, A.T., O'Shea, J., Tapsell, L., Williams, P., 2014. What do the terms wellness and wellbeing mean in dietary practice: an exploratory qualitative study examining women's perceptions. J. Hum. Nutr. Diet. 27 (4), 401-410. https://doi.org/10.1111/ jhn. 12165 .

McMahon, A.T., Williams, P., Tapsell, L., 2010. Reviewing the meanings of wellness and well-being and their implications for food choice. Perspectives in Public Health 130 (6), 282-286. https://doi.org/10.1177/1757913910384046.

Meiselman, H.L., 2016. Quality of life, well-being and wellness: measuring subjective health for foods and other products. Food Qual. Prefer. 54, 101-109. https://doi.org/ 10.1016/j.foodqual.2016.05.009.

Mialon, V.S., Clark, M.R., Leppard, P.I., Cox, D.N., 2002. The effect of dietary fibre information on consumer responses to breads and "English" muffins: a cross-cultura study. Food Qual. Prefer. 13 (1), 1-12. https://doi.org/10.1016/S0950-3293(01) 00051-9.

Miller, G., Foster, L.T., 2010. Critical Synthesis of Wellness Literature. University of
Victoria Faculty of Human and Social Development \& Department of Geography.

Mojet, J., Dürrschmid, K., Danner, L., Jöchl, M., Heiniö, R.-L., Holthuysen, N., Köster, E., 2015. Are implicit emotion measurements evoked by food unrelated to liking? Food Res. Int. 76, 224-232. https://doi.org/10.1016/j.foodres.2015.06.031.

Møller, P., 2015. Satisfaction, satiation and food behaviour. Curr. Opin. Food Sci. 3, 59-64. https://doi.org/10.1016/j.cofs.2015.02.008.

Mora, M., Giussani, B., Pagliarini, E., Chaya, C., 2019. Improvement of an emotional lexicon for the evaluation of beers. Food Qual. Prefer. 71, 158-162. https://doi.org/ 10.1016/j.foodqual.2018.06.007.

Mora, M., Urdaneta, E., Chaya, C., 2018. Emotional response to wine: sensory properties, age and gender as drivers of consumers' preferences. Food Qual. Prefer. 66, 19-28. https://doi.org/10.1016/j.foodqual.2017.12.015.

Ng, M., Chaya, C., Hort, J., 2013. The influence of sensory and packaging cues on both liking and emotional, abstract and functional conceptualizations. Food Qual. Prefer. 29 (2), 146-156. https://doi.org/10.1016/j.foodqual.2013.03.006.

Oliveira, D., Ares, G., Deliza, R., 2017. Influence of intrinsic and extrinsic factors on consumer liking and wellbeing perception of two regular and probiotic milk products. J. Sensory Stud. 32 (3), e12261. https://doi.org/10.1111/joss.12261.

Reis, F., Alcaire, F., Deliza, R., Ares, G., 2017. The role of information on consumer sensory, hedonic and wellbeing perception of sugar-reduced products: case study with orange/pomegranate juice. Food Qual. Prefer. 62, 227-236. https://doi.org/10 1016/j.foodqual.2017.06.005.

Schifferstein, H.N.J., Oude Ophuis, P.A.M., 1998. Health-related determinants of organic food consumption in The Netherlands. Food Qual. Prefer. 9 (3), 119-133. https://doi. org/10.1016/S0950-3293(97)00044-X.

Shimizu, T., 2003. Health claims and scientific substantiation of functional foodsJapanese system aiming the global standard. Curr. Top. Nutraceutical Res. 1, 213-224. https://doi.org/10.1201/b17349-21.

Silva, A.P., Jager, G., van Zyl, H., Voss, H.-P., Pintado, M., Hogg, T., De Graaf, C., 2017. Cheers, Proost, Saúde: cultural, contextual and psychological factors of wine and beer consumption in Portugal and in the Netherlands. Crit. Rev. Food Sci. Nutr. 57 (7), 1340-1349. https://doi.org/10.1080/10408398.2014.969396.

Steptoe, A., Pollard, T.M., Wardle, J., 1995. Development of a measure of the motives underlying the selection of food: the food choice questionnaire. Appetite 25 (3) 267-284. https://doi.org/10.1006/appe.1995.0061.

Strong, K., Mathers, C., Epping-Jordan, J., Beaglehole, R., 2006. Preventing chronic disease: a priority for global health. Int. J. Epidemiol. 35 (2), 492-494. https://doi. org/10.1093/ije/dyi315.

Thomson, D.M.H., Crocker, C., Marketo, C.G., 2010. Linking sensory characteristics to emotions: an example using dark chocolate. Food Qual. Prefer. 21 (8), 1117-1125. https://doi.org/10.1016/j.foodqual.2010.04.011.

Tobin, B.D., O'Sullivan, M.G., Hamill, R.M., Kerry, J.P., 2012. Effect of varying salt and fat levels on the sensory and physiochemical quality of frankfurters. Meat Sci. 92 (4), 659-666. https://doi.org/10.1016/j.meatsci.2012.06.017.

Tuorila, H., 2007. Sensory Perception as a Basis of Food Acceptance and Consumption. Consumer-led Food Product Development Woodhead Publishing limited, Cambridge, pp. 34-65.

Zellner, D.A., Loss, C.R., Zearfoss, J., Remolina, S., 2014. It tastes as good as it looks! the effect of food presentation on liking for the flavor of food 4 . Appetite 77, 31-35. https://doi.org/10.1016/j.appet.2014.02.009. 